\title{
Vruchtbare 'nutteloosheid': het belang van algemene vorming in de context van beroepsgerichte academische opleidingen
}

\author{
W. Derkse
}

\section{Samenvatting}

Academische vorming van geneeskundestudenten is meer dan het verwerven van theoretische en praktische kennis en vaardigheden. Verruimende algemene vorming met vakken die buiten de eigen discipline of de toekomstige beroepsuitoefening liggen, lijkt op het eerste oog nutteloos, maar blijkt betekenisvol en vruchtbaar te zijn. In diverse technische onderwijsprogramma's in de Verenigde Staten blijkt de toegevoegde waarde van deze elementen aan de opleiding groot te zijn. Het invullen van vrije ruimte in de opleiding met 'nutteloze' vakken (bijvoorbeeld musicologie, antieke wijsbegeerte en kunstgeschiedenis) kan een belangrijke bijdrage leveren aan het functioneren van de toekomstige artsen. (Derkse W. Vruchtbare 'nutteloosheid': het belang van algemene vorming in de context van beroepsgerichte academische opleidingen. Tijdschrift voor Medisch Onderwijs 2004;23(1):57-63.)

\section{De vruchtbare filosofische vorming van een bankdirecteur}

Wegens een feestelijke aangelegenheid bij de Tilburgse economische faculteit werd een geslaagde en landelijke bekende alumnus geïnterviewd door het plaatselijke universiteitsblad 'Univers': Herman Wijffels, toen hoofddirecteur van de Rabobank, nu al weer enkele jaren voorzitter van de Sociaal-Economische Raad. Van welke colleges in zijn economie opleiding had hij het meeste profijt gehad in zijn professionele leven?

Wijffels kwam met een antwoord dat de journalist verraste: "Van de filosofiecolleges van Loeff en Plattel!" De vragenstelster had een ander antwoord verwacht: colleges macro-economie of marketing, misschien? Waarom had Wijffels nou juist het meeste aan die filosofiecolleges gehad? Zou hij zich nog de feitelijke inhoud van die colleges herinneren? Dat zal waarschijnlijk nog maar in beperkte mate het geval zijn. Maar bij Loeff en Plattel leerde hij enkele zaken of eerder houdingen, die blijkbaar vrucht bléven dragen.
Het grondig leren lezen van een tekst, zonder daar meteen 'iets van te vinden' het is goed pas aan je oordeel toe te komen als je een kwestie begrepen hebt. Het je leren verplaatsen in de argumentatie van een ander, en daarin de sterke punten te leren zien - zonder blind het eigen standpunt achterna te hollen. Het in contact leren komen met belangrijke bronnen uit de ideeëngeschiedenis, die je oriënterende perspectieven bieden in de domeinen van cognitieve, esthetische en morele kwaliteit. Loeff en Plattel hadden hem leren lezen en denken, en hem in contact gebracht met in zekere zin tijdloze bronnen van waarde. In deze wijsgerige vorming werden Wijffels niet de gereedschappen aangereikt voor goede financiële verslaglegging, voor effectieve marketing of voor strategisch management. Wél kwam hij in contact met ideeën, oriëntaties en waardencontexten die hem bij zijn verantwoordelijkheden rond financiële verslaglegging, effectieve marketing en strategisch management op koers konden houden. Wijsgerig denken, van 
zichzelf uit niet 'nuttig', in de zin van een middel dat een haalbaar doel dichterbij brengt, werd door Wijffels blijkbaar als zinvol en vruchtbaar ervaren.

Deze 'nutteloosheid' van de wijsbegeerte werd eens heel kernachtig geformuleerd door Martin Heidegger, een volhardend en grondig denker die zich met hart en ziel aan de filosofie toewijdde. In vier beroemd geworden stellingen drukte hij het inzicht uit dat wijsgerig denken niet tot (direct) nuttige resultaten leidt:

1. Das Denken führt zu keinem Wissen wie die Wissenschaften.

2. Das Denken bringt keine nutzbare Lebensweisheit.

3. Das Denken löst keine Welträtsel.

4. Das Denken verleiht unmittelbar keine Kräfte zum Handeln.

Vreemd dat hij en mensen als Aristoteles, Spinoza, Wittgenstein en in ons taalgebied bijzonder exemplarisch Cornelis Verhoeven (1928-2001) aan zo'n denken hun leven kunnen wijden. Vreemd ook dat een topbankier het contact met dit denken als zinvol én vruchtbaar heeft ervaren.

Maar de op het eerste oog zo negatieve stellingen over waar het (wijsgerig) denken niet toe in staat is, bevatten tegelijk enkele nuanceringen die te denken geven. De filosofie voert dan wel niet tot een wetenschappelijk weten, maar kan wel uitmonden in een weten van een ander niveau: een weet hebben van dezelfde werkelijkheid die de wetenschappen bestuderen, maar dan door de reflectie verrijkt. Geen 'nuttige levenswijsheid', maar wellicht wel een verstandig leren omgaan met existentiële vragen, die anders dan (sommige) wetenschappelijke vragen vaak niet kunnen worden opgelost, maar die wel onder ogen moeten worden gezien. Filosofie biedt geen oplossingen van kleinere of grotere raadsels - dat is meer iets voor denksporters -maar kan wel de onuitputtelijkheid van het bestaansmysterie verder uitdiepen. Filosofie is er niet op gericht direct het handelen aan te sturen (dan is het eerder een ideologie geworden), maar kan wel stimuleren om in het handelen een prudente verstandigheid (sapientia) te cultiveren.

Wijffels' ervaring staat niet op zichzelf, zo heb ik in een piepklein en methodologisch onverantwoord sociologisch 'onderzoek' gemerkt. Geprikkeld door zijn uitspraak heb ik de voorbije jaren een aantal wat oudere en 'succesvolle' alumni (en wel niet-filosofen) in mijn 'netwerken' (tijdens VNO-NCW bijeenkomsten van werkgevers, op Rotaryclubs, in seminars die ik leidde) in enigerlei formulering de vraag gesteld van de 'Univers'-redactrice. Wie beschouwden zij als hun belangrijkste 'leermeesters' van hun universitaire opleidingen. Meestal hoorde ik dan niet de namen van hun afstudeerhoogleraren, maar die van filosofen als Barendse (UvA), Delfgaauw (RUG), Van Laer en Sassen (Leiden), Van Melsen (Nijmegen), Kwant (Utrecht), Luijpen (Delft) en bij de Tilburgers inderdaad opvallend vaak Loeff en Plattel. Soms ook waren het namen van niet-filosofen, maar dan toch weer exemplarische vertegenwoordigers van andere 'nutteloze' wetenschappen: Van Duinkerken (letteren), Rogier (geschiedenis), Schillebeeckx (theologie), Mohrmann (klassieke talen).

\section{Wijsgerige vorming op een technische universiteit}

Dat de opleiding in nuttige en toepasbare wetenschapsgebieden op een zinvolle manier kan worden verrijkt door het aanreiken van gedachtegoed dat daar buiten ligt, heb ik ook uit eigen ervaring kunnen waarnemen. Zeven jaren bekleedde ik met 
veel genoegen de bijzondere leerstoel Wijsbegeerte vanwege de Radboudstichting bij de Technische Universiteit te Eindhoven. Ik was trots op mijn simpele leeropdracht, vastgelegd in het Koninklijk Besluit betreffende vestiging van deze leerstoel: Wijsbegeerte. Geen nadere omschrijvingen of begrenzingen dus, zoals '... van de techniek' of '... in relatie tot de katholieke levensbeschouwing'. Niet dat ik aandacht voor technologie en natuurwetenschappen schuwde - ik ben chemicus van eerste opleiding en professie, en dat hebben mijn studenten en toehoorders natuurlijk regelmatig gemerkt, zowel in cursorische thema's als in de voorbeelden en illustraties die voorbij kwamen.

En dat ik werkzaam was vanwege de katholieke Radboudstichting zal hen evenmin zijn ontgaan, evenmin als mijn binding als oblaat aan een benedictijner abdij. Werkstukken van studenten technische bedrijfskunde over 'abbatiaal management' en een doctoraalscriptie over waardenincarnatie in monastieke architectuur getuigen daarvan. Ook het regelmatig ten tonele verschijnen van gelovige denkers als Anselmus, Thomas, Newman, Guardini, Pieper, Spaemann en Lonergan liet geen misverstand bestaan over de levensbeschouwelijke optiek van mijn leerstoel. Maar de algemeenheid van de leeropdracht Wijsbegeerte liet ik gaandeweg steeds meer prevaleren boven de door technologische gerichtheid bepaalde universitaire context waarin ik werkte en de levensbeschouwelijke optiek van mijn 'bijzondere' onderwijs, zonder de eigenstandige waarde van context en optiek ook maar enigszins te willen devalueren.

In de eerste twee jaren van mijn Eindhovense aanstelling meende ik overigens nog vrij sterk te moeten aansluiten bij de natuurwetenschappelijk-technologische context, met onder meer cursussen over de esthetiek van de natuurwetenschappen, over milieufilosofie en rond het denken van Carl Friedrich von Weizsäcker en Hendrik Casimir. De laatste kon zelfs te gast zijn in één van de sessies. Maar gaandeweg koos ik steeds vaker voor algemeenwijsgerige thema's en auteurs: cursussen 'inleiding in de wijsbegeerte', wijsgerige ethiek en wijsgerige antropologie, aandacht voor thema's als vriendschap, het goede leven en management als spirituele opdracht, langzame lectuur van teksten van Plato, Aristoteles, Marcus Aurelius, Spinoza, Nietzsche, Guardini, Pieper, De Dijn, Verhoeven - die regelmatig te gast was en mij een trimester verving.

Vanwaar deze wending in mijn onderwijsaanbod? Deels omdat ik bij mijn studenten en toehoorders het verlangen bespeurde om juist op algemeen-wijsgerige thema's te reflecteren. Onderwerpen als 'duurzame ontwikkeling', wetenschapsfilosofie en toegepaste ethiek worden al in andere TUE-cursussen voortreffelijk aangeboden. Maar het verruimen van de eigen reflectiehorizon aan de hand van centrale thema's en denkers uit de ideeëngeschiedenis werd als een welkome verbreding ervaren.

Maar naast dit verlangen bij de doelgroep, dat als 'inspelen op de markt' zou kunnen worden opgevat, was er ook een meer inhoudelijke motivatie voor de wending in mijn aanpak.

\section{Wetenschap en wetenschapstoe- passing behoeven wetenschaps- externe oriëntaties}

In mijn colleges in Eindhoven passeerde vaak een one-liner van Albert Einstein de revue, die bij het bovenstaande aansluit: "Science can tell us what is, not what should be; we need religion for that." Zoals bij iedere one-liner is enige nuancering nodig; tegelijk zit er wat in. 
Een eerste nuancering. De wetenschappen kunnen ons slechts in beperkte zin vertellen 'wat er is'; veel wat er is - en wat belangrijk is - laat zich niet meten, kwantificeren, helder beargumenteren, éénduidig uitspreken, baseren op intersubjectief toetsbare evidenties. Denk aan fenomenen als genegenheid, vreugde, dankbaarheid, zorg, vriendschap, schoonheid. Op een andere manier vinden we deze onderscheiding tussen wat zich wetenschappelijk 'zeggen' laat en belangrijke ervaringen waarvan je wel weet hebt en die zich tonen laten, maar waarvan we geen wetenschap hebben, bij Wittgenstein tegen: "We hebben allemaal het gevoel dat zelfs wanneer alle mogelijke wetenschappelijke vragen beantwoord zouden zijn, de werkelijke levensvragen nog niet eens aan de orde zijn gekomen." Vandaar dat hij Ludwig von Ficker, de verhoopte uitgever van zijn Tractatus (waaruit dit citaat stamt), ter toelichting schrijft: "Mijn boek bestaat uit twee delen. Het eerste deel kon ik schrijven en heb je nu in handen. Het tweede deel kon ik niet schrijven, maar is wel het belangrijkste deel." Dat tweede deel zou over het schone, het goede en het religieuze zijn gegaan.

Een tweede nuancering. Het is zeker niet alleen 'de religie' (op zichzelf een ongedifferentieerd 'containerbegrip') die oriënterend kan werken bij het zoeken naar een antwoord op de vraag naar 'what should be'. Er zijn ook niet-religieuze waardencontexten die oriënterend kunnen werken. Wél is het zo - en dat is het inzicht dat in Einstein's one-liner klinkt - dat de waardenoriëntatie extern is aan het veld waarin de koers moet worden uitgezet. Zoals in Plato's verhaal van de stuurman (uit de Politeia - een dialoog die over goed 'sturen' gaat) de transcendente sterrenhemel, waar de stuurman nóch bij kan nóch naar toe wil, maar die de oriëntatie biedt om de juiste pragmatische beslissing te nemen. Opnieuw Wittgenstein: "In deze [wetenschappelijk 'zegbare' WD] wereld is niets van waarde; als dat wel zo was zou het niet van waarde zijn." Waarden transcenderen het 'zee-oppervlak' van wetenschap en technologie. Bovendien komen waarden niet alleen voor - ze maken deel uit van waardencontexten die worden doorverteld en voorgeleefd.

Algemeen-wijsgerig onderwijs in de context van een technische universiteit kan studenten gevoelig maken voor de kracht en de schoonheid van wetenschap en technologie, maar ook voor het besef dat er 'meer' is dan dit prachtige en succesvolle 'zee-oppervlak', dat dit 'meer' van esthetische en morele betekenis is, en dat dit 'meer' existentieel belangrijk is.

Algemeen-wijsgerig onderwijs vanuit een 'bijzonder' perspectief kan bovendien gevoelig maken voor het feit dat sommige waardencontexten ook religieus zijn, verwijzend naar een band met wat groter is dan wijzelf en dat respectvol geïncarneerd kan worden in hoe we met dingen en mensen omgaan.

\section{Fraaie 'Amerikaanse toestanden'}

Mijn ervaringen in Eindhoven laten zich doortrekken naar andere beroepsopleidingen, zoals de medische of de juridische, en ook naar een andere 'nutteloze' maar wel zinnige inbreng dan die van wijsgerige aard. Dat je dat als universiteit ook veel serieuzer en gerichter kunt aanpakken dan met het laten vestigen van enkele bijzondere leerstoelen voor algemeen vormende vakken, kunnen we leren van een aantal gerenommeerde universiteiten in de Verenigde Staten - waar in het algemeen in het hoger onderwijs het klassieke Bildungs-ideaal (daar liberal education geheten) veel hoger in het vaandel staat 
dan op het continent waar het begrip Bildung zijn wortels heeft.

Een mooi voorbeeld daarvan. Tijdens een sabbatical op Boston College (zelf ook al een voortreffelijk voorbeeld van een instelling die de Bildungs-idealen cultiveert) maakte ik ook enkele kennismakingsbezoekjes aan het Massachuchets Institute of Technology (MIT), een iets grotere (zo'n 10.000 studenten) zusterinstelling van de TU Eindhoven. Maar als je naar de plaats van de sociale en humane wetenschappen (waaronder de wijsbegeerte) kijkt, is er een wereld van verschil. In de lijn van de Amerikaanse 'liberal arts' traditie bestaat het curriculum voor iedere B.Sc.-graad voor de helft uit wiskunde, natuurwetenschappen en technische vakken en voor de andere helft uit humane en sociale wetenschappen. In die vakken kun je trouwens doorgaan tot en met het doctoraat. Deze opzet heeft natuurlijk consequenties voor de opbouw van de wetenschappelijke staf. In 1999 telde ik op de afdeling muziekwetenschappen (!) van het MIT qua formatie (uitgedrukt in Nederlandse equivalenten) $6 \mathrm{HL}, 3 \mathrm{UHD}$ en 6 UD. Dat is ook wel nodig: de aankomend technoloog die een minor muziekwetenschappen in zijn B.Sc. wil opnemen, moet daarin 18 studiepunten halen. Voor een major zijn 33 studiepunten nodig. En dat zijn dan geen cursussen over 'muziek en technologie', maar vakken als harmonieleer, contrapunt, compositie, de structuur van Bachs Kunst der Fuge.

Bij een Nederlandse technische universiteit zou een voorstel voor de oprichting van een afdeling muziekwetenschappen als tamelijk absurd worden afgedaan.

Ook de afdeling wijsbegeerte van het MIT mag er zijn: 5 HL, 2 UHD, 4 UD. En dan geen vakken als 'ethiek van de techniek' en milieufilosofie - dat soort vakken valt onder het eveneens stevig opgetuigde
'Program in Science, Technology and Society', maar de klassieke wijsgerige vakken: antieke, middeleeuwse en moderne wijsbegeerte, kennisleer en metafysica, wijsgerige antropologie en esthetica, wijsgerige ethiek en godsdienstfilosofie.

\section{Universitaire opleidingen: niet alleen van professionals, maar ook van verantwoordelijke burgers}

Waarom vinden ze op het MIT sociale en humane wetenschappen zo belangrijk?

Ik heb er gewoon naar gevraagd. Om te beginnen geloven ze daar inderdaad nog gewoon in het aloude Bildungs-ideaal, waarvan het noemen bij sommige universitaire baasjes hier hoofdschudden en laatdukkend gesnuif veroorzaakt. Maar in Boston heeft men nog gewoon oog voor het specifiek academische van een universiteit. Verder heeft men er goed ingezien dat hun afgestudeerden na een decennium nog maar zelden in een puur technische of natuurwetenschappelijke functie werkzaam zijn. De meesten dragen dan managementverantwoordelijkheden, sturen hele groepen mensen en gecompliceerde processen aan en dragen niet zelden ook nog verantwoordelijkheden in publieke functies. Universitair opgeleiden komen inderdaad vaak in posities terecht waarin ze het leven van velen in de samenleving kunnen beïnvloeden. Dan zijn niet alleen de vragen van belang wat men tijdens de opleiding dient te leren, op welke wijze, en om welke redenen, maar ook de vraag tot wie we onze studenten helpen uitgroeien. Martha Nussbaum stelt in haar boek Cultivating Humanity dat wetenschappelijke opleidingen ook opleidingen tot burgerschap dienen te zijn. Een universiteit als een plek waar de humaniteit dient te worden gecultiveerd, zal volgens Nussbaum ook antwoord moeten geven op de vraag: "What sort of 
citizens are our colleges trying to produce, and how well are they succeeding in this task?" Als docenten leiden we toekomstige burgers op in een tijdvak van culturele diversiteit en toenemende internationalisering, in een complexe wereld van snelle verbindingen en wereldwijd in elkaar grijpende sociaal-economische processen. Voor Nussbaum rust het cultiveren van de humaniteit door onze wetenschappelijke instellingen op twee pijlers: het stimuleren van wat klassiek 'the examined life' wordt genoemd, en het stimuleren van een alerte sensibiliteit voor vragen en noden die voorbij de belangen van het ego en de eigen groep liggen. In beide pijlers gaat het om processen van intellectuele horizonverruiming; in beide ook om processen die maatschappelijk van belang zijn. Het stimuleren van 'the examined life' wordt door Nussbaum als volgt omschreven: “... developing the capacity to reason logically, to test what one reads or says for consistency of reasoning, correctness of fact, and accuracy of judgment."

Het stimuleren van de alerte sensibiliteit voor kwesties die voorbij het eigen ego en de eigen groep liggen brengt Nussbaum in verband met het versterken van de 'narratieve verbeeldingskracht': het zich leren verplaatsen in de verhalen van anderen, waardoor kennen kan groeien naar herkennen en erkennen. Zo kan sociaal-economische, politieke en andere besluitvorming met meer waardigheid en doordachte consistentie plaatsvinden, vanuit het inzicht dat de wereld meer is dan een marktplein van conflicterende belangen, en dat er zoiets als het bonum commune dient te worden gezocht. Beide pijlers die hier door Nussbaum naar voren worden gebracht schragen de ervaring die Herman Wijffels tot zijn boven geciteerde uitspraak bracht.

\section{Tenslotte}

Er pleit dus veel voor dat de verbeeldingsen besluitvormingshorizon van onze studenten wordt vergroot met enkele domeinen van waarde. Dat men in de ingenieursof artsenopleiding grondig kennismaakt met sociale en humane wetenschappen is natuurlijk geen garantie op wijs bestuur en verantwoordelijk management. Maar in ieder geval zijn oriënterende bronnen aangereikt. Zoals Loeff en Plattel dat deden aan de jonge Herman Wijffels.

Verruimende algemene vorming lijkt op het eerste oog nutteloos voor de toekomstige beroepsuitoefening, maar op het tweede gezicht blijkt deze toch ook betekenisvol en vruchtbaar te zijn. Wanneer ik een medische opleiding in elkaar zou mogen zetten, zou ik vanuit dit ervaringsinzicht een flink percentage verplichte vrije ruimte laten inruimen, die dan vervolgens niet wordt ingevuld met vakken die toch weer dicht bij de eigen discipline of de toekomstige beroepsuitoefening liggen (bijvoorbeeld wat extra microbiologie, beleidswetenschappen, zorgmanagement), maar op het eerste oog heel ver daar vandaan: liturgiewetenschappen, musicologie, franciscaanse spiritualiteit, antieke wijsbegeerte, kunstgeschiedenis. Ik denk dat beroepsdomeinen waarin medici functioneren ervan zouden opfleuren.

\section{Literatuur}

1. Derkse W., De universiteit als dienstbare gemeenschap - Een reflectie op het snijvlak van wetenschap, samenleving en levensbeschouwing, oratie KU Nijmegen, 2002.

2. Nussbaum M., Cultivating Humanity: A Classical Defense of Reform in Liberal Education, Cambridge (Mass), 1997.

3. Pelikan J., The Idea of the University - A Reexamination, Yale University Press 1992.

4. Pieper J., Was heisst Akademisch? Zwei Versuche über die Universität heute, München 1952/1964. 
De auteur:

Prof. dr. W. Derkse, opgeleid als chemicus en als filosoof, is momenteel wetenschappelijk directeur van het Soeterbeeck-programma voor Wetenschap, Samenleving en Levensbeschouwing van de KU Nijmegen. Tevens bekleedt hij de aan dit programma verbonden Andreas van Melsen Leerstoel.
Correspondentieadres:

Http:://www.soeterbeeck.kun.nl.

\section{Summary}

A university's task in educating medical doctors entails more than providing students with the required theoretical and clinical knowledge and skills. At first sight, it may not seem very fruitful to broaden the education of future doctors by the addition of subjects outside the chosen discipline or future profession. Nevertheless, subjects from domains outside medicine, such as the humanities, have proved to be a highly valued addition to various technical training programmes in the United States. Electives in subjects, such as musicology, classical philosophy and history of art can make an important contribution to future doctors' professional performance. (Derkse W. Fruitful 'irrelevance': the value of unrelated academic subjects in university courses for vocational training. Dutch Journal of Medical Education 2004;23(1):57-63.) 